\title{
Obligaciones concurrentes o in solidum (Corte Suprema)
}

\author{
Comentario de Pamela Mendoza-Alonzo*
}

Santiago, veintiséis de enero de dos mil diecisiete.

\section{VISTOS Y CONSIDERANDO:}

Primero: Que se ha ordenado dar cuenta, conforme lo dispone el artículo 782 del Código de Procedimiento Civil, de los recursos de casación en el fondo deducidos por las demandadas contra la sentencia de la Corte de Apelaciones de Antofagasta que revocó la de primera instancia en la parte que rechazó la demanda respecto de las demandadas Transportes Polar S.A. y Embotelladora Andina S.A., y la confirmó con declaración, condenando a todas las demandadas al pago solidario de las sumas de $\$ 200.000 .000$ a favor de la demandante Isabel Maldonado Carvajal y \$75.000.000 para doña Jayleen Marzán Maldonado, además de las costas de la causa.

Segundo: Que la recurrente Ana Díaz García E.I.R.L. denuncia infringido el artículo 2.330 del Código Civil, porque no se aplicó pese a haberse acreditado que el trabajador fallecido se expuso imprudentemente al daño, por lo que solicita se invalide la sentencia impugnada y se rebajen las indemnizaciones decretadas a las sumas de $\$ 30.000 .000$ y $\$ 10.000 .000$, respectivamente, o a aquellas que este tribunal determine.

La recurrente Rendic Hermanos S.A. sustenta el recurso en la contravención a los artículos $1.511,2.314$ y 2.317 del Código Civil, ya que la participación de su representada en los hechos no constituye un cuasidelito cuya coautoría pueda compartir con las restantes demandadas, lo que impide la correcta aplicación del artículo 2.137 del Código Civil, sin que tampoco concurra otra circunstancia que permita establecer una

* Licenciada en Ciencias Jurídicas, Universidad Católica de Temuco. Doctora en Derecho, Universidad de Salamanca, España. Profesora de Derecho Civil, Universidad de La Frontera. Correo electrónico: pamela. mendoza@ufrontera.cl.

Este trabajo se ha desarrollado con el financiamiento de CONICYT Proyecto FONDECYT N 11170872 "Pluralidad de responsables por un daño. Configuración del estatuto jurídico aplicable en Chile" y del proyecto DIUFRO DFP17-0009 de la Dirección de Investigación de la Universidad de La Frontera, en los que la autora es investigadora responsable. 
responsabilidad solidaria de su parte, solicitando se invalide la sentencia y se dicte una de reemplazo que rechace la demanda a su respecto.

La recurrente Transportes Polar S.A. señala como infringido el artículo 2.317 del Código Civil, toda vez que no se acreditó ningún hecho propio de su parte que pueda considerarse como causante del accidente sufrido por el trabajador, lo que hace improcedente la aplicación de la norma citada a su respecto, solicitando se invalide la sentencia y se dicte una de reemplazo que la excluya de entre aquellas demandadas obligadas al pago de las indemnizaciones otorgadas.

La recurrente Embotelladora Andina S.A. sostiene la vulneración a los artículos $2.317,1.437,1.558,2.314$ y 2.329 del Código Civil, afirmando que no se estableció la existencia de un solo hecho cometido por todas las demandadas que pueda servir de fundamento a la responsabilidad declarada por los jueces, sin que el hecho que se atribuye a su representada haya podido causar el accidente de que se trata, por lo que solicita se invalide la sentencia, dictando una de reemplazo que rechace la solidaridad decretada y declare que los perjuicios sufridos por los demandantes no son imputables a su parte.

Tercero: Que los sentenciadores del fondo tuvieron por acreditados los siguientes hechos:

1.- El día 07 de diciembre de 2013, alrededor de las 9:15 horas, el menor de edad Benjamín Vega Maldonado, hijo y hermano de las demandantes, quien prestaba servicios a la demandada Ana Díaz García E.I.R.L., sufrió un accidente de trabajo a consecuencia del cual falleció.

2.- La empleadora directa del adolescente no adoptó todas las medidas necesarias para proteger su vida y salud, falleciendo en circunstancias que realizaba descarga de bebidas de fantasía en la vía pública, zona sin demarcación, ni señalización, sin contar con elementos de protección personal, ni con un proceso de inducción para las labores que realizaba.

3.- La empresa Ana Díaz García E.I.R.L. prestaba servicios a la contratista Transportes Polar S.A., quien, a su vez, lo hacía para Embotelladora Andina S.A., quien vendía productos a la demandada Rendic Hermanos S.A., quien no contaba con un procedimiento correcto para la descarga y entrega de productos. Sobre la base de tales hechos y las omisiones en que incurrió cada demandada y el modo en que contribuyeron al accidente fatal, cuya ocurrencia se explica por el concurso de acciones imprudentes y negligencias de cada una de ellas, habiendo causado una profunda aflicción a las demandantes, quienes son madre y hermana del trabajador fallecido, se acogió la demanda, condenando a las demandadas a pagar solidariamente indemnizaciones de perjuicios que se regularon en la suma de $\$ 200.000 .000$ a favor de la demandante Isabel Maldonado Carvajal y \$75.000.000 para doña Jayleen Marzán Maldonado, además de las costas.

Cunto: Que respecto, primeramente, de la infracción de ley denunciada por Ana Díaz García E.I.R.L., la sentencia establece que las instrucciones de la recurrente, empleadora directa de la víctima -joven trabajador que perdió la vida en el accidente-, lo expusieron a la probabilidad del daño, al ordenarle hacer la carga y descarga de bebidas 
de fantasía en la vía pública, sin tomar los resguardos mínimos necesarios para proteger su vida y salud, razón por la cual hace una correcta interpretación del artículo 2.330 del Código Civil, al desestimar su aplicación al caso, ya que fluye de los antecedentes antes descritos que no hubo por parte del trabajador una acción imprudente o temeraria que le sea atribuible.

Quinto: Que, en lo que dice relación con las restantes alegaciones referidas precedentemente, de los recurrentes Rendic Hermanos S.A., Transportes Polar S.A., y Embotelladora Andina S.A., cabe señalar que no se advierten las infracciones de ley acusadas, toda vez que la sentencia impugnada tuvo por acreditada la existencia de la relación entre cada una de las demandadas y el trabajador fallecido, así como las acciones ejecutadas y omisiones de cada una de ellas y el modo en que estas concurrieron en la ocurrencia del accidente, aplicando correctamente los jueces del fondo las normas citadas por las demandadas, tanto en cuanto se determina su responsabilidad en el hecho dañoso, como en cuanto se establece la naturaleza de aquella, disponiendo que cada demandada deba concurrir solidariamente al pago de las indemnizaciones decretadas, sin que sea posible para este tribunal modificar las conclusiones a que han arribado los sentenciadores, sin alterar previamente los hechos que se han dado por acreditados, lo que resulta improcedente atendida la naturaleza del recurso y desde que no se han denunciado infracciones a las normas reguladoras de la prueba. En lo referente, concretamente, a la calificación de la participación de cada uno de los demandados en "un mismo hecho" -el atropello- (considerando vigésimo segundo), lo que lleva a aplicar la regla de la solidaridad del artículo 2.317 del Código Civil, que impugnan los recurrentes, es lo cierto que, aún en el evento de sostenerse que se ha incurrido en un error de derecho, no tendría influencia en lo dispositivo del fallo, por cuanto de igual modo debiera llegarse a la conclusión de que al haberse establecido que cada uno de los demandados, con su conducta, contribuyó a la producción del resultado dañoso, son obligaciones concurrentes que los hace responder de la totalidad del daño causado, en forma indistinta y hasta la concurrencia del monto total del mismo, por lo que si el daño lo repara uno, exonera al otro, circunstancia que si bien no es un caso de solidaridad, opera como tal y corresponden a lo que en doctrina se conoce como "obligaciones concurrentes o in sólidum".

Sexto: Que, en definitiva, los sentenciadores efectuaron una correcta interpretación de las normas jurídicas pertinentes al caso, por lo que no cabe sino concluir que el arbitrio debe ser desestimado en esta etapa de su tramitación por adolecer de manifiesta falta de fundamento.

Por estas consideraciones y normas legales citadas, se rechazan los recursos de casación en el fondo deducidos contra la sentencia de treinta y uno de agosto de dos mil dieciséis, escrita a fojas 622 y siguientes.

Regístrese y devuélvase con sus agregados.

$\mathrm{N}^{\circ}$ 95.110-2016.- 
Pronunciado por la Cuarta Sala de la Corte Suprema integrada por los Ministros señor Ricardo Blanco H., señoras Gloria Ana Chevesich R., Andrea Muñoz S., Ministro Suplente señor Alfredo Pfeiffer R, y la Abogada Integrante señora Leonor Etcheberry C. No firman el Ministro señor Blanco y el Ministro Suplente señor Pfeiffer, no obstante haber concurrido a la vista y al acuerdo de la causa, por estar con licencia médica el primero y por haber terminado su periodo de suplencia el segundo. Santiago, veintiséis de enero de dos mil diecisiete.

\section{Comentario}

El presente comentario se centra principalmente en el considerando quinto, pues la sentencia en comento es una de las más recientes en la que la Corte Suprema se refiere a la categoría de las obligaciones concurrentes o in solidum. En ella se confirma la sentencia que condenó solidariamente a empresas principal, contratista y subcontratista a pagar una indemnización a los familiares del trabajador fallecido en un accidente de tránsito ocurrido mientras descargaba un camión de bebidas. Sin embargo, obiter dicta el máximo Tribunal aclara que de todas formas los demandados habrían sido condenados a pagar el todo y no una cuota de la indemnización, pues se trata de obligaciones que en doctrina se conocen como obligaciones concurrentes o in solidum.

La obligación concurrente o in solidum ha sido tradicionalmente una categoría de obligaciones ajena a nuestro derecho. Esta ha surgido por vía jurisprudencial y doctrinal en aquellas latitudes en las que no existe una norma como el artículo 2317 del código civil chileno (que expresamente consagra la solidaridad si un delito o cuasidelito ba sido cometido por dos o más personas, por el perjuicio procedente del mismo delito o cuasidelito) y que paralelamente establecen el llamado "principio de no presunción de la solidaridad"1 en términos parecidos a nuestro artículo 1511 del Código Civil. En consecuencia, si la solidaridad debe ser expresamente pactada, los múltiples responsables por un daño tendrían que responder entonces solo por su cuota o parte en esos ordenamientos. Para evitar esa consecuencia, los tribunales (franceses, belgas, por ejemplo) han debido crear esta figura alternativa, amparándose en el principio in dubio pro damnato o favor victimae, que mira a proteger en primer lugar los intereses del perjudicado por un daño en caso de duda.

Así, se dice que la obligación concurrente o in solidum se fundamenta en la idea de indivisibilidad, ante la imposibilidad de dividir las responsabilidades pese a tener su origen de diversas causas y tener diversidad de objeto ${ }^{2}$. En ese sentido, se sostiene que su origen radica en la fuerza de las cosas, ya que surge sin convención o ley ${ }^{3}$. No es una obligación solidaria, porque solo coinciden en el principal efecto, que es que el acreedor

${ }^{1}$ Término acuñado por Hernández Gil, A., "El principio de la no presunción de la solidaridad (Tendencia hacia su crisis y delimitación)", en Revista de Derecho Privado, año XXXI, No 359, febrero 1947, pp. 81-96.

${ }^{2}$ Nos hemos detenido a revisar las características de la obligación in solidum previamente en MendozaAlonzo, P., La obligación solidaria impropia, La Ley, Madrid, 2015, pp. 53-57.

${ }^{3}$ Mendoza-Alonzo, P., cit., p. 52. 
(víctima) puede reclamar por el todo a cualquiera de los deudores (responsables extracontractuales) y el pago de la deuda total por uno de los deudores extingue la obligación principal. En todo lo demás, es decir, los efectos secundarios de la solidaridad, no le son aplicables.

Uno de los países en los que se ha aplicado con más frecuencia es Francia, donde encontramos un sinnúmero de sentencias y desarrollo doctrinal que se originan prácticamente a la par del nacimiento del Código de Napoleón ${ }^{4}$. Por otra parte, destaca en España la figura de la "obligación solidaria impropia”, creación jurisprudencial cuyo origen obedece a similares circunstancias que la obligación in solidum francesa ${ }^{5}$. Sin embargo, ni en la actual reforma al Código Civil francés ${ }^{6}$ ni en el proyecto de reforma al Código español en materia de obligaciones y $\operatorname{contratos}^{7}$ se contempla su consagración legal pese al desarrollo jurisprudencial y doctrinal. Por su parte, tampoco las iniciativas armonizadoras del derecho de obligaciones y contratos en Europa (por ejemplo PECL, $D C F R$ ) la consideran expresamente como una modalidad de pluralidad de deudores. Algo distinto ha sucedido en Argentina (en el que este tipo de obligaciones también ha sido tradicionalmente considerado por su doctrina y jurisprudencia ${ }^{8}$ ), pues el nuevo Código Civil y Comercial de la Nación de 2014 las acepta expresamente en su artículo 850, definiendo a las obligaciones concurrentes como aquellas en las que varios deudores deben el mismo objeto en razón de causas diferentes. Así también, al regular la pluralidad de responsables, el artículo 1751 del código argentino distingue claramente que (s) i varias personas participan en la producción del daño que tiene una causa única, se aplican las reglas de las obligaciones solidarias. Si la pluralidad deriva de causas distintas, se aplican las reglas de las obligaciones concurrentes.

Aclarado lo anterior, en Chile existe una tendencia incipiente que acepta este tipo de obligaciones tanto a nivel doctrinal ${ }^{9}$ como jurisprudencial, así como se aprecia en la sentencia comentada. Esto porque la solidaridad del artículo 2317 no es aplicable a todos los casos en que exista pluralidad de responsables por un daño, por lo que queda una zona gris en la que los tribunales no han podido determinar pacíficamente si el

\footnotetext{
${ }^{4}$ Por ejemplo, Français, J., De la distinction entre l'obligation solidaire et l'obligation "in solidum", Éditions internacionales, Paris, 1936; Chabas, F., “Remarques sur l'obligation 'in solidum”, en Revue Trimestrielle de Droit Civil, No 65, 1967, pp. 310-338; Mignot, M., Les obligations solidaires et les obligations in solidum en droit privé français, Dalloz, Paris, 2002, etc.

${ }^{5}$ Por todos, véase, Mendoza-Alonzo, P., cit.; Esteve Pardo, M., La solidaridad impropia deudores, Marcial Pons, Madrid, 2014.

${ }^{6}$ https://www.legifrance.gouv.fr/

${ }^{7}$ http://www.mjusticia.gob.es/cs/Satellite/Portal/1292427518878

${ }^{8}$ Por todos, véase Bueres, A., "Las obligaciones concurrentes en la jurisprudencia argentina", en Revista de Derecho Privado y Comunitario, Vol. 1, 2005, pp. 387-404.

${ }^{9}$ Peñailillo Arévalo, D., Obligaciones. Teoría general y clasificaciones. La resolución por incumplimiento. Jurídica, Santiago, 2003, pp. 306-307; Barros Bourie, E., Tratado de responsabilidad extracontractual. Santiago, Chile: Jurídica, 2006, pp. 423-425; Corral Talciani, H., "Obligaciones por el total no solidarias u obligaciones concurrentes”, en Severin Fuster, G., Mejías Alonzo, C., Vidal Olivares, A. (ed.), Estudios de Derecho Civil X. Jornadas nacionales de derecho civil, Valparaíso 2014, Thomson Reuters, Santiago, 2015, pp. 452-471.
} 
caso concreto califica como obligación solidaria o no ${ }^{10}$ (por ejemplo, casos de causalidad adicional, responsabilidad por miembro indeterminado de un grupo, responsabilidades directas, etc.). Asimismo, aunque exista claridad de que no se aplica el artículo 2317 , como en situaciones de causalidad concurrente, en los que cada hecho por sí solo hubiese sido suficiente para causar el daño o responsabilidad por causas de atribución diversas ${ }^{11}$ (como parece entender el tribunal en el caso comentado), el principio favor victimae inhibe de condenar por cuota o parte de la indemnización, por lo que condenar por el total in solidum, parece ser la solución más equitativa.

No obstante, salvo un reciente trabajo del profesor Corral, quien las denomina "obligaciones por el total no solidarias"12 y sentencias aisladas (como la sentencia de la Corte Suprema Rol 7524-2015 de 4 de mayo de 2016 ${ }^{13}$ ) no se ha profundizado mayormente acerca de sus fundamentos o principios comunes o respecto de las consecuencias de admitirlas en nuestro derecho, por lo que el debate recién comienza.

${ }^{10}$ Como lo advierte Corral, cit., p. 458.

${ }^{11}$ Corral, cit., p. 466.

12 Corral, cit., pp. 452-471.

${ }^{13}$ Así explica en el considerando sexto que “(...) surgen dos obligaciones con distintos deudores, con la particularidad de que son concurrentes, por lo que si el daño lo repara uno, ese pago exonera al otro. Si bien no es un caso de solidaridad, a la postre opera como tal ya que comparten el rasgo esencial de las obligaciones propiamente solidarias, cual es que se puede reclamar a cada deudor el total de la obligación y una vez pagada, el otro puede oponer la excepción de pago. Eso, respecto de la obligación a la deuda, cosa distinta es lo que ocurra a la hora de ejercer acciones restitutorias, en el ámbito de la contribución a la deuda. Como es posible observar, la figura responde a lo que en doctrina extranjera se conoce como obligaciones concurrentes o in solidum (como sostiene el profesor Hernán Corral comentando el fallo de esta Corte, rol N ${ }^{\circ}$ 10.139-2013)". 